\title{
Boomerang hiring: Strategy for sustainable development in COVID-19 era
}

\author{
P.V. Raveendra* and Y.M. Satish \\ Department of Management Studies, M S Ramaiah Institute of Technology, MSR Nagar, Bangalore, Karnataka, \\ India
}

Received 30 November 2020

Accepted 14 January 2021

\begin{abstract}
.
BACKGROUND: Many companies are forced to restructure themselves by right sizing due to unexpected fall in demand for their products and services created by the COVID-19 pandemic. COVID 19 not only affected the health of human beings but also their wealth across the world. Global economic parameters are showing a sign of positive growth with decreased number of COVID 19 cases across the world. Many companies are in a dilemma to rehire their former employees or to hire the new candidates to meet the increased demand.

OBJECTIVES: The objectives of study are i) to analyze the key drivers for boomerang hiring and ii) to develop a conceptual process for boomerang hiring.

METHODS: An exploratory methodology was designed to identify the key drivers of boomerang hiring by studying the various successful stories of those companies which had rehired their former employees. Various papers were reviewed to develop the process for boomerang hiring.

RESULTS: Study showed that knowledge about the culture of the company, cost of hiring, morale booster for the existing employees, and customer retention, are the key drivers for boomerang hiring. This hiring process requires special skills from HR Managers, as this decision will impact long term success of the company.

CONCLUSION: The process of boomerang hiring cannot be standardized as each organization culture is different and companies cannot have the same strategy for each candidate as every individual is different. Boomerang hiring will work as the right strategy during pandemic situation as former employees would have built relations with the customers. The customers will be happy to see the former employees who had served them better.
\end{abstract}

Keywords: Boomerang hiring, key drivers for boomerang hiring, training for former employees, return of former employees

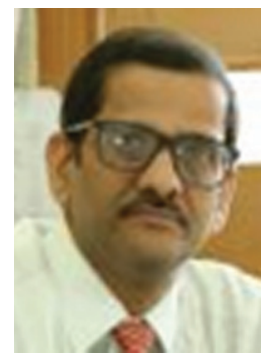

Dr. Penumadu Venkata Raveendra is working as Professor, Department of Management Studies, MS Ramaiah Institute of Technology, Bengaluru (affiliated to VTU) and heading the research centre. His areas of interest include financial services and CRM. He has co-authored a book on "Wealth Creation through Entrepreneurship", "Security Analysis and Portfolio Management" and "Change and Knowledge Management". He has published more than 25 papers in journals, national and international conferences and has published articles in various management journals. He had guided eight research scholars in various universities. Convener

${ }^{*}$ Corresponding author: Dr. Penumadu V. Raveendra, Department of Management Studies, M S Ramaiah Institute of Technology, MSR Nagar, Bangalore, Karnataka, 560054, India. Tel.: +918023603123; Fax: +918023603124; E-mail: raveendrapv@ msrit.edu.. ORCID ID: 0000-0002-6057-4546 for various sponsored national seminars by ICWA, ICSSR and AICTE. He had written more than five book chapters in various books. www.msrit.edu ORCID ID: 0000-0002-6057-4546

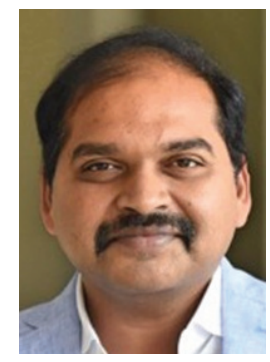

Dr. Yellappa Murthy Satish is the Professor in Department of Management Studies, M.S. Ramaiah Institute of Technology, Bengaluru (affiliated to VTU). His areas of interests include Research, Current affairs, Startup \& Venture Capital, Turn Around Management and MSME. He has published more than 20 research papers in national, international journals and national and international conferences. He has co-authored book on "Security Analysis and Portfolio Management". He had written more than three book chapters in various books. He is the Principal investigator for various research funded projects under ICSSR and DST. www.msrit.edu ORCID ID: 0000-0002-6828-4164 


\section{Introduction}

COVID 19 has thrown fresh challenges to the volatile, uncertain, complex and ambiguous (VUCA) world on talent acquisition and management. To maintain sustainable success, the companies should build customer retention successfully. To have successful retention of the customers, companies should retain the employees successfully. Fourth industrial revolution which in indexed as 4.0 lead to many like industry 4.0, Work 4.0, in both human resources plays an important role [1]. It is the time for re opening of the industry and economy across the globe, however the second wave of new positive cases has put a threat to this [2]. However, the pandemic situation has forced to rewrite the HR strategies. In the name of restructuring, right sizing, many companies had reduced their employees count irrespective of their contributions and competencies. With improved economic conditions many ogranisations are optimistic about their future growth. However, these companies are in a dilemma. Is it better to hire new candidates or re hire the former employees? Rehiring of former employees is not a new concept which is known as 'boomerang hiring'. In this pandemic situation boomerang hiring will work as right strategy due to various benefits of the same. It might be in terms of fitting into the culture, savings in cost of recruitment and training, etc., Once company decides to go for boomerang hiring, again the question arises, shall we rehire all the employees or selected employees only? If so, what should be the basis for it? It is common phenomenon to attract the high performing employees who have joined other organizations and enhance their competencies that suit the job requirements of present and future [3, 4]. This is quiet common among MNCs, for example Mr. Steve Jobs was a boomerang hired employee who rejoined Apple after 12 years of gap. The success of Apple will be attributed to iPod and IPhone which are brainchildren of Mr. Steve Jobs. During his second tenure he was able to take the company's market capitalization from $\$ 3$ billion to $\$ 347$ billion. It happened in the sports also. Michel Jordan was another boomerang hired employee who quit NBA for three championships of professional baseball and back to the parent team who made the history [5].

According to Karle Group H R Manager Mr. Vasudev "do not expect that all the employees who left or forced to leave, will come back and join." In his company during the lockdown period some of the employees were forced to resign. However, after the improved economic condition, they want those employees to come back but many of them did not turn up. Of course the company had offered lower salary this time.

However, acceptance of this concept is not so ease among the companies unless they are aware of the benefits and the key drivers for boomerang hiring. Strategy give an action plan for achieving the objectives. Boomerang hiring as a strategy should develop the process for attracting the former employees successfully.

\section{Boomerang hiring: Theoretical perspective and drivers}

There are three types of employees who left the organization. They are a) early leavers who leave the company within one year of joining. They leave the organization in search of suitable jobs according to their ambitions and some of them will leave for higher studies. Organizations had spent a lot of investment on them in terms of recruitment and training. These employees may not be interested to come back to the organization. Boomerang hiring is not suitable strategy for such candidates as these candidates are still in learning stage and building competencies. b) Top performers who quit after contributing their best to the organizations. Their loss might have affected the company in a considerable way and they might have acted as growth engines of the company. These employees constitute a major portion. These are the target candidates for boomerang hiring strategy since they have required competencies. During pandemic era searching for the potential candidates with such competencies from the general pool is a challenging job. Human resource Manager can plan a suitable boomerang hiring strategy to attract these former employees to rejoin the company. c) Universal leaders who were responsible for sustenance and daily operations and worked with the organization for considerable period. They are the part and parcel of building the organization culture and value system. They are completely aware about the organization business. Again these candidates are also target group for boomerang hiring strategy if they wish to come back. HR Manager should be able to convince such suitable former employees because they had proven track record [6]. Every organization should identify the right candidates with good performance and plan for rehiring such employees $[3,4]$. Of course until now we are discussing from organization's point of 
view, it is equally important to think from the former employee's point of view. Former employee's perception and intention towards rejoining the same company is equally important. These candidates have to plan their stay with the organization and some of them might demand for key roles in the organization $[4,7]$. After conducting an interview with $1800 \mathrm{HR}$ professionals, [8] Majority of them ready to consider rehiring former employees and there is a growing desire among former employees to rejoin the previous organization. This is because former employees also enjoy certain benefit from this strategy. Familiarity with the culture, familiarity with people, policies, processes and guidelines make them to return to the organization.

The Corporate Culture and Boomerang Employee study by Workplace Trends after doing survey with HR Professionals had come up with some interesting findings. The percentage of employees who had rejoined the company is $15 \%$. Interestingly the percentage of employees who will consider to rejoin the previous company if given a chance is around $40 \%$. However, the number of HR professionals who are ready to accept hiring boomerang employees is $76 \%$. The positive rate of hiring the ex employees who had shown interest is only 50\%. $60 \%$ of the HR managers are not ready to take the ex employees [9]. One should know both sides of the coin about employees and employers. American Society of Employers had done a survey with employees and found the reasons what make them not to come back to the previous company. According to the study $22 \%$ of them dissatisfied with the management or superior, $17 \%$ of them opined that they are not able fit into the organization culture and $13 \%$ opined that they are not able fulfil the job requirements and $13 \%$ opined that it was not smooth exit and they have burnt the bridges between the company and them [10]

\section{Research methodology}

Various research papers are reviewed to study the concept of boomerang hiring and to develop the process of boomerang hiring process.

\subsection{Objectives of the study}

1. To analyze the key drivers for boomerang hiring

2. To develop process for boomerang hiring

\section{Analysis and findings}

\subsection{Drivers of Boomerang hiring strategy}

The following are the key drivers of boomerang hiring strategy regarding its stake holders.

\subsubsection{Culture}

Fitting into the culture of the organization is most important than any other element for an employee. The familiarity of the organization culture is a positive aspect in boomerang hiring strategy [11] (Raj \& Hundekar, 2013). Ex-employees are completely aware about the culture and fit into the culture easily when compared to an external candidate. Many employees who left the organization after working long period of time find difficulty to fit into the new organization culture. Every organization will have its own unique culture. Employee engagement is possible when the employees fit into the organizational culture. Taking a chance with new candidates who were selected on the basis of competencies or skills may backfire when they did not fit into the organization culture. Thus boomerang hiring is the suitable strategy during this tough times. At the same time the commitment levels of such employees will be much higher as they have seen real world outside the organization and the desire to succeed will be more [12].

\subsubsection{Cost}

'A penny saved is a penny earned' is the suitable proverb during all the times and in particular during the economic slowdown. All the stakeholders should make saving wherever possible in the organization. By using boomerang hiring strategy organization will save lot of funds. Because when compared to other sources of recruitment, boomerang hiring cost of hiring will be the lowest. Cost of advertisement, cost of conducting interviews and many other costs like induction program are saved to the company. At the same the candidate might have learnt some new competencies when he was outside of the organization. All these will add value for supporting boomerang hiring strategy during economic slowdown [3]. Because of his new assignment, employees are expected to spend more time in the organization and thus contributing to the organization.

\subsubsection{Cost of training}

New employees have to go through the induction process and training. However, in case of boomerang 
hiring there is no need for induction and training as they have already gone through the process. There is a possibility that ex-employees might have acquired new skills or competencies in the other organizations which is an added value to the organizations. With the boomerang hiring strategy the former employee may also bring some of the best practices of other organizations.

\subsubsection{Increased morale}

Boomerang hiring can act as strategic in nature when the organization actively targets the skilled former employees. They realized the real worth of the employee and poach him to return to the organization. This is not a new practice in the global organization [13]. It is common practiced in the MNCs like Mc.Kinsey, E \& Y, Deloitte and so on. In these companies, boomerang hiring is one of the prime recruitment methods [14].

Reactive boomerang is possible when the former employees of the organization apply for the position in their previous organization. The boomerang hiring becomes ease when the employee has clearly communicated his willingness to return to the company in future in his exit interview [15]. When the organization conduct the proper exit interview with $t$ respect, ensuring that the employee leave with a positive note, thereby paving way for favorable post exit relationship [16].

The founder CEO of Integrity Marketing Consulting opined that boomerang hiring will boost the morale of the employees and it will spread a sense of belonging ness and happiness in the workplace which will be helpful to increase the employee retention. The reappearance of former employees is a real validation of brand of the employer [17].

New employees are better or ex employees are better is cleared by MakeMyTrip Chief human resource officer, the success rate among the new hires is only 75 i.e. $25 \%$ might turn out to be average performers, while success rate with boomerang strategy is $100 \%$

\subsubsection{Behavior intention}

The intention of the former employees is crucial for rejoining. Behaviour intention is a degree to which a person has consciously planned to perform a behaviour. However, the exit of the former employee should be smooth and in healthy manner. In such cases the Behaviour intention will be positive and chances of returning is more [18].

\subsubsection{Alumni relations and communication}

The long lasting relationships are not build in one day. It requires continuous effort by not only from HR department but also from the other department employees. The regular interaction and sharing of the required information will be helpful for building the relationship. When such relationships are maintained the rejoining of the former employee will be more. Technology plays an important role in communication. Organizations can have a separate website for its alumni and maintain good rapport with formers employees. This is in addition to email communication [19] (Mael, \& Ashforth, 1992). Former employee might be happy to participate in the functions of previous organization because this is an opportunity for them to meet all his former colleagues. Boomerang hiring can be started from these function where there is social gathering of many friends. Managing Director EMEA and AMER at Resource solutions observed, "One should make use of all channels to procure best talent including regretted leavers".

\subsection{Boomerang hiring process}

\subsubsection{Identify the employees who are eligible}

Not all the employees who left are good and potential. HR manager should have complete data regarding the employees who left the organization and the reasons for leaving. If any employee is sent out on disciplinary grounds he need not to be considered for rehiring. Any former employee with attitude and ethical problems need not to be considered. Employees who left for salary alone may again leave the company. Candidates with good track record and left the company for valid reasons can be considered provided they have regularly upgraded their skills. Those skills may be useful for the company in the present or future. MakeMyTrip, one of the Nasdaq listed company assign a code to employee who leave the company or asked to quit. The employees who are assigned code 1 can be hired later depending on the requirement. The employees who are assigned code 2 can be considered for hiring after due diligence and those who are assigned with code 3 will be not be hired at any cost [20] (Singh, 2020).

\subsubsection{Conduct the formal interview and on boarding}

Rehiring the farmer employees does not mean without interview. HR manager can treat them as new candidate and candidate has to be introduced 
to the latest changes in the company and the current projects. Of course the company need not spend as much time as it spends on an outsider. After accepting the job by former employee, put them through a formal on boarding process.

\subsubsection{Communicate the current employees about the employee's return}

To get the desired benefits of the boomerang hiring it is important to inform to all the employees about the employee's return. It will act as the morale booster for the existing employees.

\subsubsection{Feedback and review}

Unless the employee has positive contribution, the purpose of the boomerang hiring will not be met. Listen to their suggestions and implement whatever feasible in the organizational context. At the same time he or she has to be observed regularly and feedback has to be taken from such employees so that he will not leave the organization again [21] (hrexchangenetwork,2020). Joel Paul, GM India of RiseSmart, is so optimistic about the performance of boomerang employee, he said that they will start delivering the goods from second week onwards.

Software Advice surveyed and found that $80 \%$ of workers opined that their former employer does not have any policy or strategy in their human resource plan [17]. However there are exceptions in term of Mr.Nadeesh from KPMG who himself is returned employee to KPMG, " the policy decision of the company is such that any employee who is returning the company will be taken in the same position and lower position but definitely not higher positon in the company".

"Not only have boomerangs already been through the company's learning curve, we actually think they are more loyal not less, because it shows they have affection for us" Mike Blackburn, MD of digital marketing agency I-COM.

\section{Conclusion}

Before concluding about this paper the following interesting case let about one of the leading software giants.

Learning from Boomerang hiring: WIPRO Infotech is India's second biggest software company, which is known for its service quality throughout the world. It has written policy for boomerang hiring except those who are forced to leave with flag. (Flag is given to the employees who are gone against the values of the company, or done some malpractices). All other employees are allowed to apply to return to the company. Mr. Avaneesh was a project leader and left the company. He was expert in that particular project. After six months he would like to come back and the company welcome him, however Mr. Avaneesh had successfully negotiated for higher salary. This tactic of Mr. Avaneesh's had become as trend for many employees. Company learnt the lesson and re written the policy such that no boomerang-hired employee will be taken for higher salary and there should be minimum gap of two years before returning the company. Now one has to plan the strategy how to deal with such employees like Mr. Avaneesh.

However, E \&Y runs a 'post-exit probe', under which the company reaches out to employees two months after their departure, to reinitiate contact and ask how well they may be settling in at the new workplace. "If things aren't working out, we explore the opportunity for that employee to return to us," said Sandeep Kohli, national director-HR.

Fitting into the culture, savings in recruitment process and training are some of the key drivers of boomerang hiring strategy. In addition to the above there are some qualitative benefits which will arise through this strategy. Boomerang hiring will be a big morale booster for the existing employees in the organization. The process of boomerang hiring cannot be standardized as each organization culture is different and the company cannot have the same strategy for each candidate as every individual is different. Boomerang hiring will work as right strategy during pandemic situation as former employees would build the relations with the customers. The customers will be happy to see the former employees who had served them better. Even though many companies are ready for rehiring former employees, they do not have a documented re hiring policy. Mr Jagadish Ahuja CEO of Financial services opined that "it depends on the need of the hour, it did not work for me in the past and it is too difficult to take action against such employee if they underperform". The chance of boomerang hiring will increase when there is shorter period between person leaving and rejoining. This is the exact situation where we are today, due to pandemic situation there are temporary fluctuations in business environment. With improved economic conditions, boomerang hiring will be right strategy for the organizations. 


\section{Acknowledgments}

The authors have no acknowledgments.

\section{Author contributions}

CONCEPTION: Penumadu V. Raveendra and Yellappa M. Satish

METHODOLOGY: Penumadu V. Raveendra and Yellappa M. Satish

DATA COLLECTION: Penumadu V. Raveendra and Yellappa M. Satish

INTERPRETATION OR ANALYSIS OF DATA: Penumadu V. Raveendra and Yellappa M. Satish PREPARATION OF THE MANUSCRIPT: Penumadu V. Raveendra

REVISION FOR IMPORTANT INTELLECTUAL CONTENT: Penumadu V. Raveendra and Yellappa M. Satish

SUPERVISION: Penumadu V. Raveendra and Yellappa M. Satish

\section{References}

[1] Popescua S, Santaa R, Teleaba F, Ilesana H. (2020, July). A structured framework for identifying risks sources related to human resources in a 4.0 working environment perspective. Human Systems Management. 2020;39:511-27. DOI: 10.3233/HSM-201034

[2] Jesusa T, Landry M, Jacobs K. A new normal following COVID-19 and the economic crisis: Using systems thinking to identify challenges and opportunities in disability, telework, and rehabilitation. Work. 2020;37-46. DOI: 10.3233/WOR-203250

[3] Sullivan J. End your recruiting without spending a dime. Workforce Management. 2006; pp. 6.

[4] Hart A. Karen. Boomerang recruitment: bridging the gap. Nursing Economics. 2009;27(1):56-63.

[5] Hyman J. 2019. https://www.forbes.com. March 13. Accessed December 6, 2020. https://www.forbes.com/sites/jeff hyman/2019/03/13/boomerang/?sh=7ee98519058d

[6] Anubha B. Talent Retention in IT sector, SCMHRD Wednesday, 21 March 2012

[7] Warshaw PR, Davis FD. Self-understanding and the accuracy of behavioral expectations. Personality and Social Psychology Bulletin. 1985;10:111-8.
[8] Cavalli H. US Guide to workforce and salary trends Lee Hechit Harrison Retrieved from https://www.lhh.com/ourknowledge/2017/2017-us-guide-to-workforce-and-salarytrendsDuff, A., \& Barragan, S. (2015, March 23). Making a Comeback. Canadian HR Reporter, (2017), pp. 11.

[9] Team, B. (2010, June). An HR Glossary for HR Terms. Retrieved from BambooHR: https://www.bamboohr.com/ hr-glossary/boomerang-employee/

[10] Team, HR Network Editorial. 2019. www.hrexchangenet work.com. July 19. Accessed December 6, 20. https:// www.hrexchangenetwork.com/hr-talent-acquisition/artic les/boomerang-employees-the-pros-and-con

[11] Raj VS, Hundekar S. Developing A Successful Rehiring Model. International Research Journal of Social Science. 2013;39-42.

[12] Huhman H. (2012). Gen Y's interpersonal communication skills, Cachinko, Retrieved from https://growingleader s.com/wp-content/uploads/2014/02/061912.Cachinko.pdf

[13] Duff A, Barragan S. Making a comeback: Best practices in boomerang hiring. HR Canadian Reporter. 2015;430-70.

[14] Sullivan J. (2018, Febrauary 20). Retrieved from DR.JOHN SULLIVAN.COM: https://drjohnsullivan.com/articles/boo merangs-no-1-solution-reducing-need-hire-stranger-candi dates/

[15] Kumavat PP. Boomerang of Employees: The Strategic way of filling the Organizational Talent Gap, International Journal of Management and Social Sciences Research (IJMSSR). (2012).

[16] Kulik CT, Rae B, Sardeshmukh SR, Perera S. Can we still be friend? The role of eit converstaions in facilitation post exit. Human Resource Management. 2014;893-912.

[17] Wong K. 2020. https://www.achievers.com. January 21. Accessed December 6, 2020. https://www.achievers. com/blog/why-boomerang-employees-are-a-good-thing/.

[18] Warshaw PR, Davis FD. Self-understanding and the accuracy of behavioral expectations. Personality and Social Psychology Bulletin. 1985;10:111-8.

[19] Mael F, Ashforth BE. Alumni and their alma mater: A partial test of the reformulated model of organizational identification. Journal of Organizational Behavior. 1992;13(2):103-23.

[20] Singh S. (2020, August 20). Recovering economy: Companies looking to hire employees they had laid off seven months ago. Retrieved from The Economic Time: https://economictimes.indiatimes.com/jobs/recoveringeconomy-companies-looking-to-hire-employees-they-hadlaid-off-seven-months-ago/articleshow/79343996.cms

[21] https://www.hrexchangenetwork.com/hr-talentacquisition/articles/boomerang-employees-the-prosand-cons 